\title{
EXPERIMENTAL EVALUATION OF THE FULL-RANGE BEHAVIOUR OF STEEL BEAM-TO-COLUMN CONNECTIONS
}

\author{
Shen Yan ${ }^{1 *}$, Kim J.R. Rasmussen ${ }^{1}$, Lu-li Jiang ${ }^{1}$, Chen Zhu ${ }^{1}$ and Hao Zhang ${ }^{1}$ \\ ${ }^{1}$ The University of Sydney, Sydney, Australia \\ * (Corresponding author: E-mail: shen.yan@sydney.edu.au)
}

\section{A B S T RACT}

The paper summarises recent experimental research undertaken at the University of Sydney on determining the full-range behaviour of steel beam-to-column connections. Three series of tests were conducted on three different types of connections including bolted extended end-plate connections, top-and-seat angle connections and double web angle connections. The tests were continued well into the post-ultimate range until complete failure of the connection, obtaining the connection's full-range behaviour comprising the initial linear response, non-linear behaviour resulting from gradual yielding of connection components, ultimate state, and post-ultimate softening and fracture behaviour. The failure modes were observed and analysed for the tested connection types. Moreover, for the top-and-seat angle connections and double web angle connections, multiple tests were conducted on nominally identical connections to examine the variability of the connection behaviour, which stems from the random variation in geometric and material properties.
ARTICLE HISTORY

$\begin{array}{ll}\text { Received: } & \text { 8 November } 2019 \\ \text { Revised: } & \text { 1 February } 2020 \\ \text { Accepted: } & \text { 1 February } 2020\end{array}$

\section{K E Y W O R D S}

Bolted end-plate connection; Top-and-seat angle connection; Web angle connection;

Experiments;

Statistical data;

Full-range behaviour

\section{Introduction}

Seeing the semi-rigidity of joints affects the strength and serviceability of unbraced steel frames, a large number of studies have been carried out to investigate the semi-rigid behaviour of different types of beam-to-column joints, including bolted end-plate connections [1-3], top-and-seat angle connections [46], web angle connections [7-9], and other connection types [10-12]. Based on these studies, connection models have been proposed aimed at predicting the connection behaviour [13-15], notably the Component Method now implemented in Eurocode 3 [16].

The above many studies, especially the experimental studies, primarily focused on the initial stiffness and inelastic behaviour under small joint rotation, with little attention paid to the ultimate limit state, failure mode and postultimate response. The post-ultimate response may be of less interest in structural design against ordinary loads, where the structural members and connections primarily undergo elastic deformation, but is very important in structural design against loads induced by extreme events such as terrorist attacks. Moreover, advances in computing power and analysis software over the last decade have made it possible to perform structural design by Geometric and Material Nonlinear Analysis with Imperfections (GMNIA), or "advanced" analysis, and the understanding of the full-range performance of joints is indispensable in such structural designs.

Therefore, research programs were undertaken recently at the University of Sydney aiming at determining the full-range behaviour of various types of steel beam-to-column joints [17-20]. This paper summaries the experimental studies. Three types of steel connections were tested, including bolted extended endplate (EP) connections, top-and-seat angle (TSA) connections and double web angle (WA) connections. The connections were tested well into the postultimate range until their complete failure, and thus the failure modes and fullrange connection behaviour could be examined. The connections were subjected to a variety of load combinations, including major-axis bending, combined bending and axial force and bi-axial bending. Moreover, for the TSA and WA connections, multiple tests were conducted on nominally identical connections so as to investigate the variability of joint properties, e.g. stiffness, resistance and ductility, due to the variable geometric and material properties and the random variations in fabrication.

\section{Experimental program}

\subsection{General}

Table 1 summarises the experimental program which comprised 49 tests, including tests on $13 \mathrm{EP}$ connections (Nos. 1 13 in Table 1), 18 TSA connections (Nos. 14 31) and 18 WA connections (Nos. 32 49).

The EP connections featured two different geometric configurations, differing in the thickness of the end-plate, which was $10 \mathrm{~mm}$ for the EP10 series connections (Nos. 1 7 in Table 1) and $20 \mathrm{~mm}$ for the EP20 series connections (Nos. 8 13 in Table 1). All EP20 connections had backing plates to strengthen

Table 1

Summary of connections^.

\begin{tabular}{|c|c|c|c|}
\hline No. & Designation & Connection $^{*}$ & Loading $^{\#}$ \\
\hline 1 & EP10 & 10-EP, nо BP & B \\
\hline 2 & EP10BP & 10-EP, BP & B \\
\hline 3 & EP10_TS & 10-EP, no BP & $\mathrm{B} \&$ small $\mathrm{T}$ \\
\hline 4 & EP10_TL & 10-EP, no BP & $\mathrm{B} \&$ large $\mathrm{T}$ \\
\hline 5 & EP10_BS & 10-EP, no BP & B \& small MB \\
\hline 6 & EP10_BL & 10-EP, no BP & $\mathrm{B} \&$ large $\mathrm{MB}$ \\
\hline 7 & EP10_M & 10-EP, no BP & MB \\
\hline 8 & ЕР20BP & 20-EP, BP & B \\
\hline 9 & EP20BP_CS & 20-EP, BP & B \& small C \\
\hline 10 & EP20BP_CL & 20-EP, BP & B \& large C \\
\hline 11 & EP20BP_BS & 20-EP, BP & B \& small MB \\
\hline 12 & EP20BP_BL & 20-EP, BP & $\mathrm{B} \&$ large $\mathrm{MB}$ \\
\hline 13 & EP20BP_M & 20-EP, BP & MB \\
\hline $14 \sim 18$ & TSA360-1 5 & 360UB 56.7 & B \\
\hline $19 \sim 20$ & TSA360_T-1 2 & 360UB 56.7 & B \& $\mathrm{T}$ \\
\hline $21 \sim 22$ & TSA360_C-1 2 & 360UB 56.7 & B \& C \\
\hline $23 \sim 27$ & TSA530-1 5 & 530UB 92.4 & B \\
\hline $28 \sim 29$ & TSA530_T-1 2 & 530UB 92.4 & B \& $\mathrm{T}$ \\
\hline $30 \sim 31$ & TSA530_C-1 2 & 530UB 92.4 & B \& C \\
\hline $32 \sim 36$ & WA360-1 5 & 360UB 56.7 & B \\
\hline $37 \sim 38$ & WA360_T-1 2 & 360UB 56.7 & B \& $\mathrm{T}$ \\
\hline $39 \sim 40$ & WA360_C-1 2 & 360UB 56.7 & B \& C \\
\hline $41 \sim 45$ & WA460_1 5 & 460UB 82.1 & B \\
\hline $46 \sim 47$ & WA460_T-1 2 & 460UB 82.1 & $\mathrm{~B} \& \mathrm{~T}$ \\
\hline $48 \sim 49$ & WA460_C-1 2 & 460UB 82.1 & B \& $C$ \\
\hline
\end{tabular}

${ }^{\wedge}$ More details of specimens and results refer to [18-20] (EP - [18], TSA - [19], WA - [20])

${ }^{*}$ 10-EP $=10$-mm end-plate, 20 -EP $=20$-mm end-plate, $\mathrm{BP}=$ backing plate;

\# $\mathrm{B}=$ major-axis bending, $\mathrm{T}=$ tension, $\mathrm{C}=$ compression, $\mathrm{MB}=$ minor-axis bending; 
the end-plate, while all EP10 connections had no backing plates except for one, i.e. EP10BP, which investigated the effect of backing plates on the end-plate bending behaviour. For each connection series, four different load combinations were applied, including major-axis bending, combined bending and axial force, bi-axial bending and minor-axis bending, as shown in Table 1 .

The TSA connections featured two different geometric configurations with the difference being the beam section, which was 360UB 56.7 for the TSA360 series connections (Nos. 14 22 in Table 1) and 530UB 92.4 for the TSA530 series connections (Nos. 23 31 in Table 1). Multiple tests were carried out on nominally identical specimens, and three load combinations were considered. For each connection series, five nominally identical specimens were subjected to bending, two were subjected to combined bending and axial tension, and two were subjected to combined bending and axial compression, as shown in Table 1.

The WA connections had two different geometric configurations, featuring difference in the beam section, which was 360UB 56.7 for the TSA360 series connections (Nos. 32 40 in Table 1) and 530UB 92.4 for the TSA 530 series connections (Nos. 41 49 in Table 1). As a result of the different beam sections, different numbers of bolt rows were used to connect the double web angle cleats to the beam web and column flange. The TSA360 and TSA530 connections had three and five bolt rows, respectively. The WA connection tests were similar to the TSA connection tests in terms of load combinations and the number of tests for each load combination, as shown in Table 1.

\subsection{Specimen details}

Figure 1 shows the dimensions of the tested connections. It is noted that the TSA530 connections had larger beam size than the TSA360 connections, which led to longer flange cleats in the TSA530 connections, as shown in Fig. 1(b). Similarly, the larger beam size in the WA460 connections compared to the WA360 connections resulted in longer web angle cleats and more bolt rows, as depicted in Fig. 1(c).

All EP connections were manufactured from Grade 350 steel to AS/NZS 3679.1 [21], while all TSA and WA connections were manufactured from Grade 300 steel. The material properties of the sections, including the end-plates, the angle cleats, as well as the beams and columns, were obtained from coupon tests and are summarised in Table 2. In the EP connections, the end-plate was welded to the beam end with full strength $45^{\circ}$ continuous fillet welds, using manual metal arc welding with E48/W50X welding rods.

Table 2

Mechanical properties of materials.

\begin{tabular}{cccccc}
\hline Section & $\begin{array}{c}\text { Young's } \\
\text { Modulus } \\
(\mathrm{GPa})\end{array}$ & $\begin{array}{c}\text { Yield } \\
\text { stress } \\
(\mathrm{MPa})\end{array}$ & $\begin{array}{c}\text { Ultimate } \\
\text { strength } \\
(\mathrm{MPa})\end{array}$ & $\begin{array}{c}\text { Uniform } \\
\text { elongation }\end{array}$ & $\begin{array}{c}\text { Total } \\
\text { elongation }\end{array}$ \\
\hline 310UB 46.2 & 207 & 353 & 505 & 0.18 & 0.26 \\
310UC 96.8 & 207 & 382 & 498 & 0.20 & 0.31 \\
250UC 89.5 flange & 210 & 276 & 448 & 0.23 & 0.40 \\
250UC 89.5 web & 209 & 335 & 476 & 0.21 & 0.33 \\
360UB 56.7 flange & 201 & 306 & 479 & 0.21 & 0.35 \\
360UB 56.7 web & 210 & 336 & 476 & 0.21 & 0.33 \\
530UB92.4 flange & 203 & 294 & 452 & 0.22 & 0.37 \\
460 UB 82.1 web & 200 & 347 & 477 & 0.20 & 0.34 \\
10-mm end-plate & 205 & 425 & 567 & 0.17 & 0.25 \\
20-mm end-plate & 204 & 355 & 503 & 0.18 & 0.26 \\
125x125x8EA & 205 & 322 & 483 & 0.19 & 0.28 \\
100x100x8EA & 209 & 308 & 444 & 0.21 & 0.31 \\
\hline
\end{tabular}

\# Uniform elongation = elongation corresponding to the ultimate strength

\subsection{Test setup}

All connection types were tested using essentially the same test set-up which was constructed with several movable rig parts in order to accommodate a variety of load combinations, as shown in Fig. 2. The column ends were connected to the supports using pins, with one end fixed against displacements while the other end capable of moving in the direction of the column centreline, ensuring a simply supported condition for the column. The beam was loaded through a loading arm using a hydraulic jack installed on a stiff reaction frame.

For bending tests, the supports had the same height, and thus the beam was in the vertical direction and perpendicular to the loading arm, as depicted in Fig. 2(a). For combined bending and axial force tests, the heights of the supports were altered, introducing an angle $\left(\theta_{1}\right)$ between the loading arm and the direction perpendicular to the axis of the beam, as depicted in Fig. 2(b). This set-up generated an axial load in the beam in addition to the bending moment. By adjusting the heights of the supports and thereby changing the angle $\theta_{1}$, connections subjected to same bending moment could have different axial loads applied simultaneously. For bi-axial bending tests, the specimen was rotated about the centerline of the beam to create an angle $\left(\theta_{2}\right)$ between the loading arm and the major axis bending plane of the beam, as shown in Fig. 2(c). Similarly, different ratios between the major-axis and minor-axis bending moments were achievable by adjusting the angle $\theta_{2}$. When $\theta_{2}$ equaled $90^{\circ}$, the loading direction was along the minor-axis of the beam and the connection was subjected to minor-axis bending.
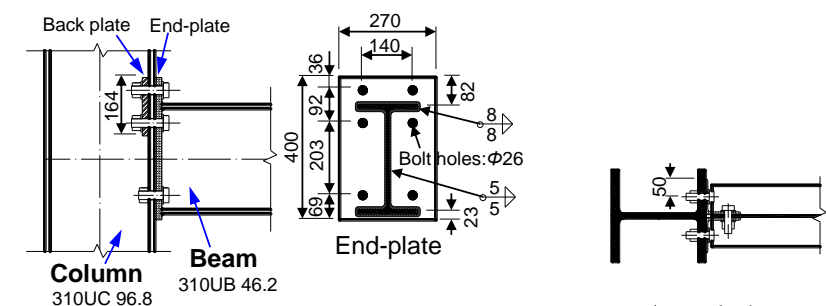

(a)
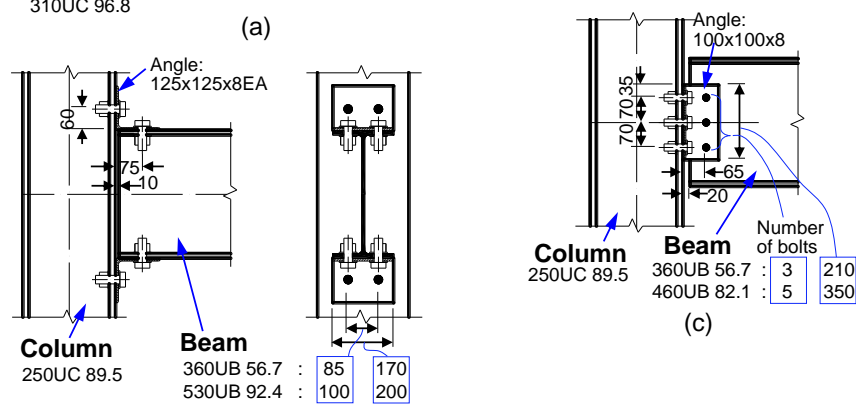

(c)

(b)

Fig. 1 Geometry of specimens (all dimensions in mm). (a) Bolted extended end-plate connections; (b) top-and-seat angle connections; (c) double web angle connections.

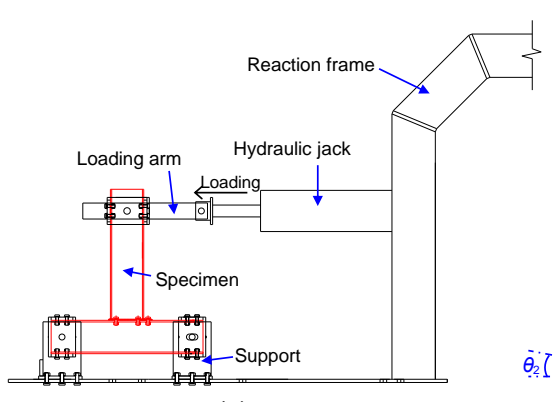

(a)

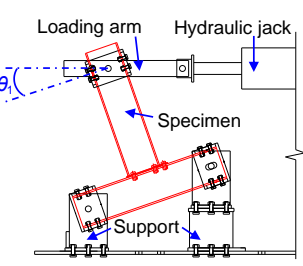

(b)

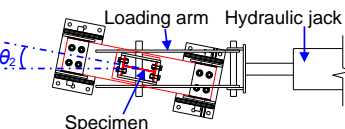

(c)

Fig. 2 Test setup. (a) Bending tests; (b) combined bending and axial force tests; (c) biaxial bending tests, and minor-axis bending tests.

\subsection{Instrumentation and test procedure}

All tests were instrumented with displacement transducers and inclinometers. All specimens were loaded using a servo-controlled hydraulic jack with a displacement rate set at $1 \mathrm{~mm} / \mathrm{min}$, and all data were recorded at 1 sec intervals. Using the measurements from the load cell, transducers and inclinometers, the bending moment and axial force applied to the connection were calculated, as was the rotation of the connection, which is defined as the relative rotation between the centerlines of the column and the beam. The detailed arrangement of the instrumentation and the equations used for calculating the moment, force and rotation can be found in [18-20].

Although load was applied slowly, the effect of strain rate on material strength is non-negligible and needs to be eliminated. Therefore, during the tests, the loading was paused for 2 mins every 10-20 mins in order to acquire the static resistance. The raw data were processed to obtain smooth continuous curves through the static resistance loading points. An example of the data processing can be found in [18]. 


\section{Experimental results for bolted end-plate connections}

\subsection{EP10 series tests}

Figure 3 presents the bending moment versus joint rotation curves of all EP10 series connections, in which the bending moment refers to the minor-axis bending moment for EP10_M, and to the major-axis bending moment for all other connections. Table 3 summarises the experimental results.
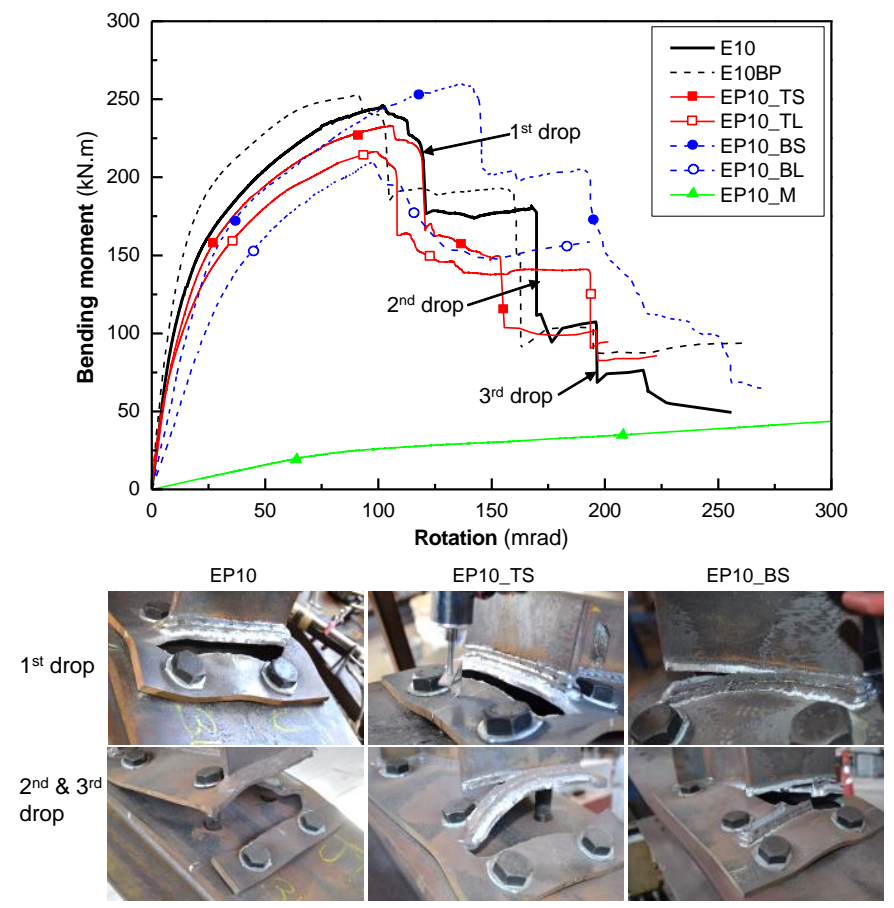

Fig. 3 Test results for EP10 series connections.

In EP10_M, which was subjected to minor-axis bending, the major source of deformation was observed to be the column flange twisting. The corresponding deformation capacity was extensive, and the connection performed essentially linearly under large joint rotation, as shown in Fig. 3. The connection did not reach its ultimate resistance under a rotation up to $0.45 \mathrm{rad}$, at which the test was terminated.

For the other connections, the main applied action was the major-axis bending moment. These connections had the same failure mode, i.e. the endplate fracture (EPF) failure mode, which featured crack initiation and propagation in the end-plate. Connection EP10 was the baseline specimen, so its behaviour is descripted in detail herein.

Connection EP10 had an initial linear response followed by a nonlinear response caused by to the gradual yielding of the connection components, the end-plate in particular, as shown in Fig. 3. Before reaching the ultimate resistance, two cracks initiated in the heat affected zone of the weld connecting the beam flange to the end-plate. The crack initiation locations were aligned with the two bolts in the extended part of the end-plate. The two cracks progressively grew wider and merged, causing the connection to reach its ultimate resistance and the subsequent first drop in bending resistance, as shown in Fig. 3. The merged crack grew around the tip of the beam flange on one side, and towards the edge of the end-plate on the other side. Eventually the propagated crack caused the extended part of the end-plate to tear off the connection, resulting in the second drop in resistance. The crack propagation continued along the weld of the inside edge of the tension flange and eventually along the weld of the web plate, leading to unloading of the inner bolt on this side. This increased the tensile force in the inner bolt on the other side, thereby causing the bolt to fracture. This marked the third abrupt drop in resistance on the moment-rotation curve and the complete failure of the connection, as shown in Fig. 3.

Connections EP10_TS and EP10_TL received additional axial tensile force, which led to smaller resistance in the gradual yielding range and smaller ultimate resistance in comparison with EP10. The additional tensile load, however, did not change the failure mode of the connections, which was characterised by a three-stage post-ultimate failure process, as shown in Fig. 3.

Connections EP10_BS and EP10BL were subjected to bi-axial bending. The additional minor-axis bending reduced both the initial stiffness and the major-axis strength over the gradual yielding range. The ultimate major-axis bending resistance of EP10_BL was 14.7\% smaller than that of EP10, while the bending resistance of EP10_BS was unexpectedly increased by $5.7 \%$. The increase in strength may be caused by random variations introduced during fabrication, including better-than-expected welding quality in this case.

Connection EP10BP used backing plates to strengthen the column flange. The backing plates increased the stiffness and the strength of the connection, but resulted in a reduction in the rotation capacity, as shown in Fig. 3. In the post-ultimate range, EP10BP experienced sequential abrupt reductions in strength similar to EP10 due to the initiation and propagation of cracks.

\subsection{EP20 series tests}

Figure 4 presents the bending moment versus joint rotation curves of all EP20 series connections, in which the bending moment refers to the minor-axis bending moment for EP20BP_M, and to the major-axis bending moment for all other connections. Table 4 summarises the experimental results.

The minor-axis bending connection, EP20BP_M, behaved similarly to EP10_M, with the major deformation arising from column flange twisting. The connection had an essentially linear response under large joint rotations, as shown in Fig. 4, and did not reach its ultimate resistance under a rotation up to $0.45 \mathrm{rad}$, at which the test was terminated.

For the other connections, the main action applied was the major-axis bending moment. These connections had the same failure mode, i.e. the column web buckling (CWB) failure mode. Connection EP20BP was the baseline specimen, so its behaviour is descripted in detail herein.

EP20BP had a 20-mm thick end-plate as well as backing plates, which greatly strengthened its performance in the tension zone. Consequently, S20BP failed in the compression zone due to inelastic buckling of the column web,

Table 3

Summary of EP10 series test results. [18]

\begin{tabular}{|c|c|c|c|c|c|c|c|}
\hline \multirow[b]{2}{*}{ Designation } & \multirow{2}{*}{$\begin{array}{c}\text { Initial stiffness } \\
(\mathrm{kN} \cdot \mathrm{m} / \mathrm{rad})\end{array}$} & \multicolumn{3}{|c|}{ Ultimate resistance } & \multirow{2}{*}{$\begin{array}{l}\text { Joint rotation at } \\
\text { ultimate resistance } \\
(\mathrm{rad})\end{array}$} & \multirow{2}{*}{$\begin{array}{l}\text { Joint ductility } \\
\text { (rad) }\end{array}$} & \multirow{2}{*}{ Failure mode ${ }^{*}$} \\
\hline & & $\begin{array}{c}\text { Major-axis moment } \\
(\mathrm{kN} \cdot \mathrm{m})\end{array}$ & $\begin{array}{c}\text { Minor-axis moment } \\
(\mathrm{kN} \cdot \mathrm{m})\end{array}$ & $\begin{array}{c}\begin{array}{c}\text { Axial force } \\
(\mathrm{kN})\end{array} \\
\end{array}$ & & & \\
\hline EP10 & 11706 & 245 & - & - & 0.103 & 0.256 & EPF \\
\hline EP10BP & 14890 & 252 & - & - & 0.092 & 0.258 & EPF \\
\hline EP10_TS & 9976 & 233 & - & 88 & 0.106 & 0.223 & EPF \\
\hline EP10_TL & 10816 & 216 & - & 140 & 0.099 & 0.201 & EPF \\
\hline EP10_BS & 6452 & 259 & 50 & - & 0.138 & 0.270 & EPF \\
\hline EP10_BL & 4050 & 209 & 93 & - & 0.098 & $0.192^{\# \#}$ & EPF \\
\hline EP10_M & 316 & - & - & - & - & $0.45^{\# \#}$ & EPF \\
\hline
\end{tabular}

* EPF $=$ End-plate fracture

\# Positive values indicate tension

\#\# Loading was terminated before complete failure of the connection; this value of the last recorded value 

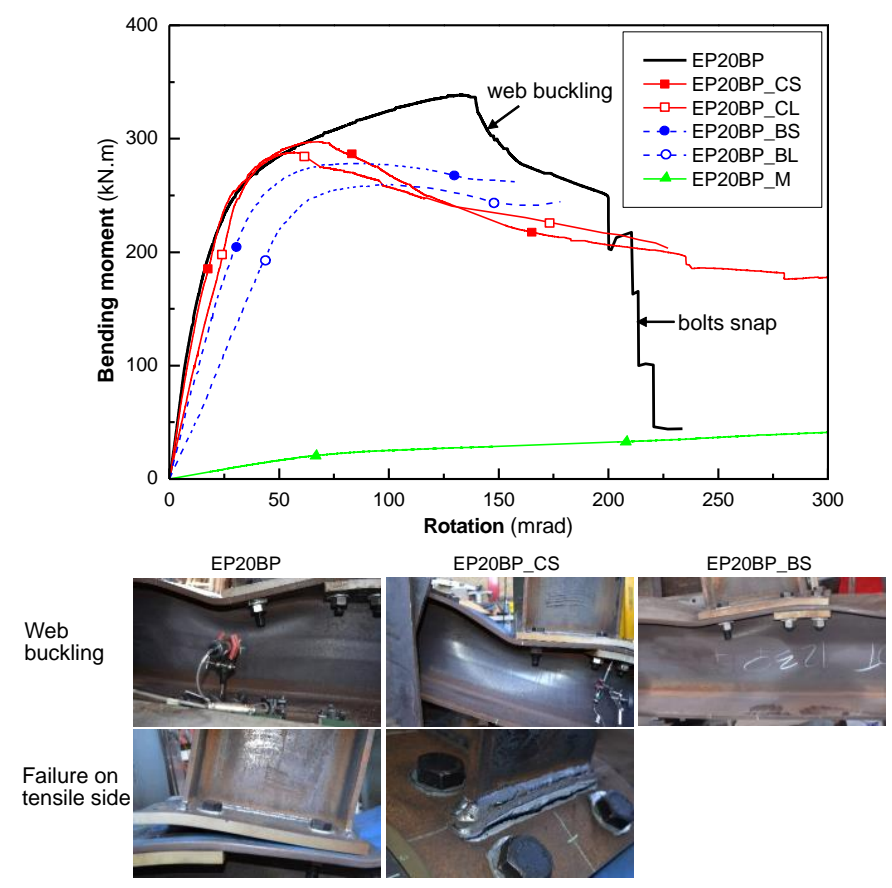

Fig. 4 Test results for EP20 series connections.

instead of in the tension zone as occurred in the EP10 series connections. The web buckling appeared when the connection approached its ultimate resistance, and triggered rapidly growing web out-of-plane deflections associated with a gradual reduction in resistance. The complete failure of the connection was caused by the fracture of the tensile bolts on the tension side, as shown in Fig. 4. The ultimate strength and corresponding rotation were significantly higher than those of the EP10 series connections.

Connections EP20BP_CS and EP20BP_CL received additional axial compression, and failed in the same CWB failure mode as EP20BP. The compressive axial load precipitated the column web buckling, and therefore both connections reached their ultimate bending resistance significantly earlier than EP20BP, as shown in Fig. 4. The post-ultimate behaviours were different from that of EP20BP. The complete failure of EP20BP_CS was due to the formation of a crack in the HAZ along the tension flange, while no component failed on the tension side in the EP20BP_CL test.

Connections EP20BP_BS and EP20BP_BL were subjected to bi-axial bending, and failed in the CWB failure mode as the other EP20 series connections did. The additional minor-axis bending reduced the initial stiffness, the ultimate strength as well as the rotation corresponding to the ultimate majoraxis bending moment, as shown in Fig. 4. For both tests, no component failure was observed on the tensile side of the connections.

\subsection{Failure mechanism}

The test results of the EP10 series connections showed that the end-plate connections with relatively thin end-plates were prone to failing in an end-plate fracture (EPF) failure mode when subjected to major-axis bending, whether or not additional axial load or additional minor-axis bending moment was applied.

Figure 5 shows a typical example of the failure process, which can be described by four stages, with the last three stages giving rise to the three drops observed on the moment-rotation curve. After the first, second and third drops, the connection preserved around $75 \%$, around $43 \%$, and below $40 \%$ of its ultimate bending strength, respectively.

The end-plate connections with a relatively thick end-plate failed as a result of column web buckling (CWB), as observed in the tests of the EP20 series connections. This failure mode featured a gradual resistance reduction in the post-ultimate range. Load combinations affected the resistance reduction rate, but all connections preserved over $70 \%$ of their ultimate strengths under large rotations up to $0.20 \mathrm{rad}$. The complete failure of the connections was caused by the fracture on the tension side, either tensile bolt fracture or crack propagation in the heat affected zone along the welds.
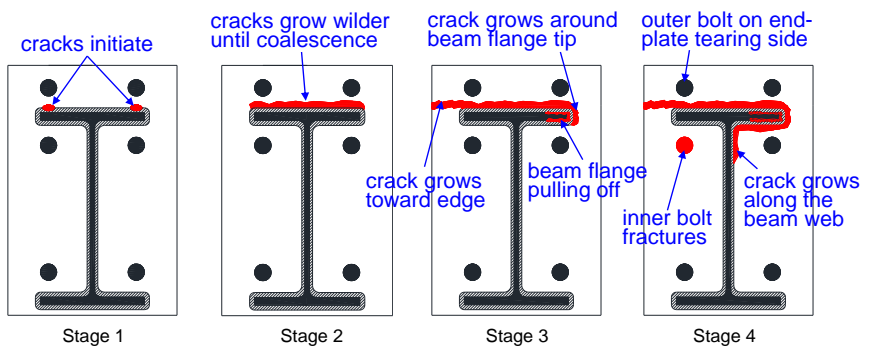

Fig. 5 End-plate fracture failure mode.

\section{Experimental results for top-and-seat angle connections}

\subsection{TSA360 series tests}

Figure 6 presents the bending moment versus joint rotation curves of all TSA360 series connections and pictures showing the connection failure mode. All connections behaved similarly and had the same failure mode, i.e. top angle fracture (TAF), but the applied axial force in addition to the major-axis bending moment affected the ultimate bending resistance and the corresponding joint rotation. Table 5 summarises the experimental results.

For TSA360-1, the initial moment-rotation response was stiff and largely linear, followed by a nonlinear response due to the gradual yielding of the joint components, the top flange cleat in particular. The bolts connecting the angle cleats slipped during the transition from the linear to the nonlinear range, forming a plateau on the moment-rotation curve, as shown in Fig. 6. Gradually, plastic hinges formed on the top flange cleat at multiple cross-sections, including the two cross-sections where the bolts connected the column leg and the beam leg, as well as the two cross-sections near the root of the cleat where its thickness changed. This constituted a major difference from the deformation pattern specified in Eurocode 3, in which the top flange cleat is modelled as an equivalent $\mathrm{T}$-stub, implying that the top flange cleat undergoes a purely horizontal displacement without rotation of the beam leg and thus does not develop plastic hinges in the beam leg. As the load approached the ultimate strength of the connection, on the top flange cleat, two cracks initiated at the surface of the column leg near the root of the cleat where the plastic hinge formed. The occurrence of the two cracks marked the ultimate bending

Table 4

Summary of EP20 series test results. [18]

\begin{tabular}{|c|c|c|c|c|c|c|c|}
\hline \multirow{2}{*}{ Designation } & \multirow{2}{*}{$\begin{array}{l}\text { Initial stiffness } \\
(\mathrm{kN} \cdot \mathrm{m} / \mathrm{rad})\end{array}$} & \multicolumn{3}{|c|}{ Ultimate resistance } & \multirow{2}{*}{$\begin{array}{l}\text { Joint rotation at } \\
\text { ultimate resistance } \\
(\mathrm{rad})\end{array}$} & \multirow{2}{*}{$\begin{array}{c}\text { Joint ductility } \\
\text { (rad) }\end{array}$} & \multirow{2}{*}{ Failure mode } \\
\hline & & $\begin{array}{c}\text { Major-axis moment } \\
(\mathrm{kN} \cdot \mathrm{m})\end{array}$ & $\begin{array}{c}\text { Minor-axis moment } \\
(\mathrm{kN} \cdot \mathrm{m})\end{array}$ & $\begin{array}{c}\text { Axial force } \mathrm{e}^{\#} \\
(\mathrm{kN})\end{array}$ & & & \\
\hline EP20BP & 13983 & 338 & - & - & 0.133 & 0.235 & CWB \\
\hline EP20BP_CS & 12372 & 297 & - & -66 & 0.067 & 0.487 & CWB \\
\hline EP20BP_CL & 8652 & 288 & - & -138 & 0.056 & 0.302 & CWB \\
\hline EP20BP_BS & 7581 & 278 & 54 & - & 0.081 & $0.156^{\# \#}$ & CWB \\
\hline EP20BP_BL & 4150 & 259 & 115 & - & 0.098 & $0.178^{\# \#}$ & CWB \\
\hline EP20BP_M & 348 & - & - & - & - & $0.45^{\# \#}$ & CWB \\
\hline
\end{tabular}

* CWB = Column web buckling 

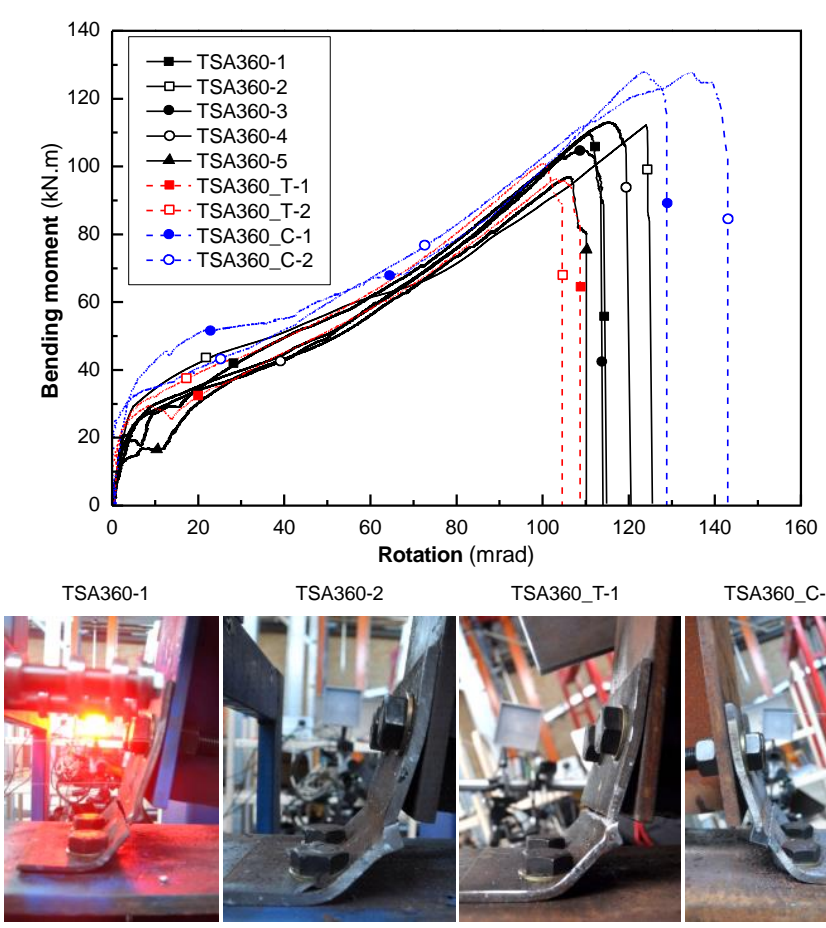

TSA360_T-1
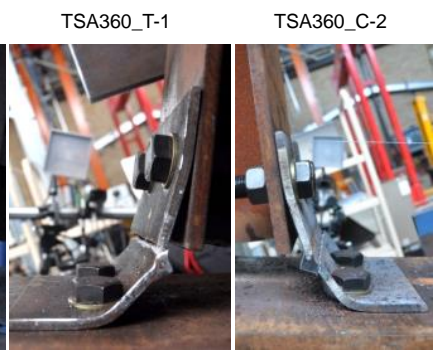

Fig. 6 Test results for TSA360 series connections.

resistance of the connection. The cracks were initially aligned with the two bolt lines, and subsequently propagated quickly to the edges of the angle cleat, as well as towards to each other. The propagation of the cracks led to a very quick reduction in the bending resistance of the connection. When the two cracks merged to form a single continuous crack, the connection failed with the load dropping instantly to zero, as shown in Fig. 6.

The other nominally identical bending connections had the same deformation pattern and failure mode as TSA360-1, but showed certain variabilities in response, demonstrating the effect of inherent variations in geometric and material properties. The CoVs of the initial stiffness, ultimate bending resistance, joint rotation corresponding to the ultimate bending resistance, and ductility of joint were $0.173,0.061,0.062$ and 0.053 , respectively. The crack that occurred in the top flange cleat could form either in the beam leg or in the column leg, as shown in Fig. 6.

Applying an axial load in addition to the bending moment did not change the failure mode, but altered the ultimate strength and the corresponding rotation. The additional tensile force accelerated the failure of the top angle cleat, thereby reducing the ultimate bending resistance, the corresponding rotation, and the joint ductility, as shown in Fig. 6. On the other hand, the additional compressive force postponed the connection failure, thereby increasing the ultimate bending resistance, the corresponding rotation, and the joint ductility.
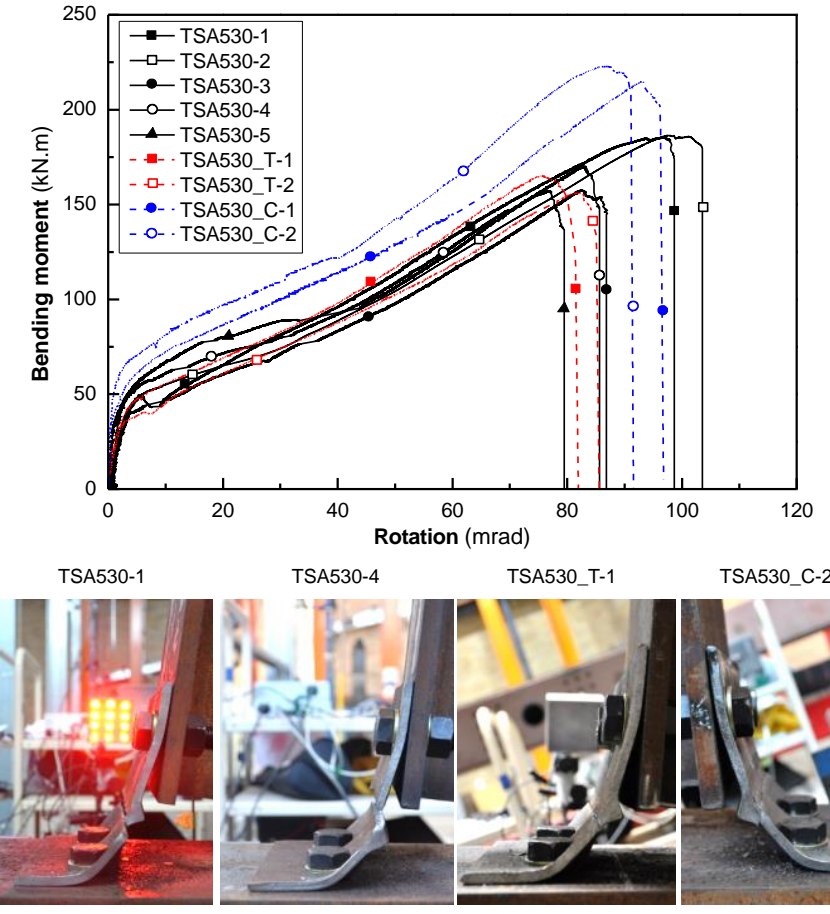

TSA530_C-2

Fig. 7 Test results for TSA530 series connections.

\subsection{TSA530 series tests}

Figure 7 presents the bending moment versus joint rotation curves of all TSA530 series connections and pictures showing the connection failure mode. In general, the connections behaved similarly to the TSA360 series connections over the full loading range, and had the same failure mode, i.e. top angle fracture (TAF). Table 6 summarises the experimental results.

Each of the TSA530 bending connections showed an initial linear response, followed by a transient stage of bolt slip, which was more pronounced for some connections than others, and a stage featuring a nonlinear increase in bending resistance, as shown in Fig. 7. During the nonlinear stage, four plastic hinges formed in the top flange cleat, two in the column leg and two in the beam leg. All connections failed in the TAF mode. Similar to the TSA360 tests, the connection failure was caused by the initiation and propagation of a crack formed at one of the two plastic hinges near the root of the top flange cleat. The joint properties were also variable. The $\mathrm{CoVs}$ of the initial stiffness, ultimate strength and corresponding joint rotation, and joint ductility were $0.537,0.087$, 0.109 and 0.107 , respectively. These CoVs were consistently larger than those for the TSA360 connections, indicating greater variation in the joint properties of the TSA530 connections.

The additional axial force in the beam affected the connection behaviour in the same way as it affected the TSA360 series connections. That is, the tensile

Table 5

Summary of TSA360 series test results. [19]

\begin{tabular}{|c|c|c|c|c|c|c|}
\hline \multirow{2}{*}{ Designation } & \multirow{2}{*}{$\begin{array}{c}\text { Initial stiffness } \\
(\mathrm{kN} \cdot \mathrm{m} / \mathrm{rad})\end{array}$} & \multicolumn{2}{|c|}{ Ultimate resistance } & \multirow{2}{*}{$\begin{array}{l}\text { Joint rotation at ultimate } \\
\text { resistance } \\
\text { (rad) }\end{array}$} & \multirow{2}{*}{$\begin{array}{l}\text { Joint ductility } \\
\text { (rad) }\end{array}$} & \multirow{2}{*}{ Failure mode ${ }^{*}$} \\
\hline & & Bending moment $(\mathrm{kN} \cdot \mathrm{m})$ & Axial force ${ }^{\#}(\mathrm{kN})$ & & & \\
\hline TSA360-1 & 8670 & 109 & 11.5 & 0.111 & 0.115 & TAF \\
\hline TSA360-2 & 8390 & 112 & 13.0 & 0.124 & 0.126 & TAF \\
\hline TSA360-3 & 5390 & 105 & 11.7 & 0.109 & 0.114 & TAF \\
\hline TSA360-4 & 7320 & 113 & 13.5 & 0.116 & 0.120 & TAF \\
\hline TSA360-5 & 7850 & 96.9 & 10.3 & 0.106 & 0.110 & TAF \\
\hline TSA360_T-1 & 19300 & 96.4 & 31.9 & 0.103 & 0.109 & TAF \\
\hline TSA360_T-2 & 25000 & 101 & 34.1 & 0.101 & 0.104 & TAF \\
\hline TSA360_C-1 & 8150 & 128 & -33.4 & 0.123 & 0.129 & TAF \\
\hline TSA360_C-2 & 21700 & 128 & -32.5 & 0.135 & 0.143 & TAF \\
\hline
\end{tabular}

$*$ TAF $=$ Top angle fracture

\# Positive values indicate tension; negative values indicate compression 
force accelerated the failure of the top angle cleat, thereby reducing the ultimate bending resistance, the corresponding joint rotation, and the joint ductility, while the compressive force was beneficial in terms of increasing the strength and ductility of the joints. The additional axial force did not change the failure mode. Hence, the connections subjected to combined bending and axial force also failed in the TAF mode, with the crack forming either in the column or beam leg of the top flange cleat.

\subsection{Failure mechanism}

Figure 8 schematically illustrates the typical process of the crack initiation and propagation in the top angle fracture (TAF) failure mode. As shown in the figure, the cracks formed in the column leg of the top flange cleat near the root of the cleat where the plastic hinge developed, and propagated to the edges. It is noted that the cracks could also form in the beam leg, as observed in some of the tests.

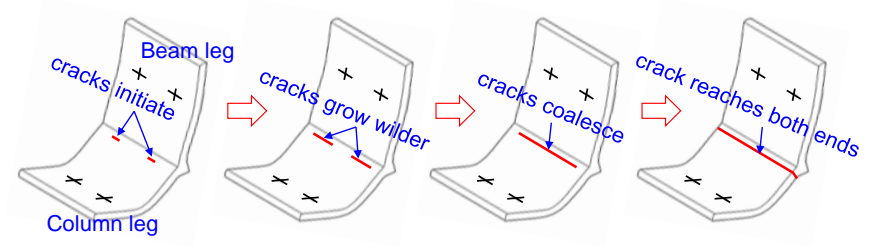

Fig. 8 Top angle fracture failure mode.

\section{Experimental results for double web angle connections}

\subsection{WA360 series tests}

Figure 9 presents the bending moment versus joint rotation curves of all WA360 series connections and pictures showing the two failure modes observed in the tests. Table 7 summarises the experimental results.

The WA360-1 connection had a linear moment-rotation response with a relatively large stiffness in the initial stage, followed by a bolt slip stage which led to a plateau on the moment-rotation curve, as shown in Fig. 9. Henceforth, the top and bottom parts of the angle cleats transmitted tensile and compressive loads, respectively, through bearing of bolts, and the moment resistance of the joint increased significantly. Due to the yielding of the joint components, the joint stiffness gradually decreased until the joint rotation brought the compressive flange of the beam into contact with the face of the column flange. The contact made the beam bottom flange the new centre of compression, leading to an increase in the lever arm between the parts of the connection transferring compression and tension. After contact was established, the moment resistance and joint stiffness increased dramatically. As the joint approached its ultimate strength, a crack initiated near the root of each web angle cleat aligning with the top bolt row, and progressively propagated towards both edges of the cleat, causing a significant reduction in the moment resistance. This mode of failure is referred to as the web angle fracture (WAF) mode. The other nominally identical bending connections behaved similarly to WA360-1, as demonstrated by the similar moment versus rotation curves, featuring slip of bolts, contact between the beam bottom flange and the column flange, and the WAF failure mode. However, noticeable variations were observed in the joint properties. The CoVs of the initial stiffness, ultimate bending resistance, joint rotation corresponding to the ultimate resistance, and joint ductility were $0.194,0.062,0.082$ and 0.152 , respectively.
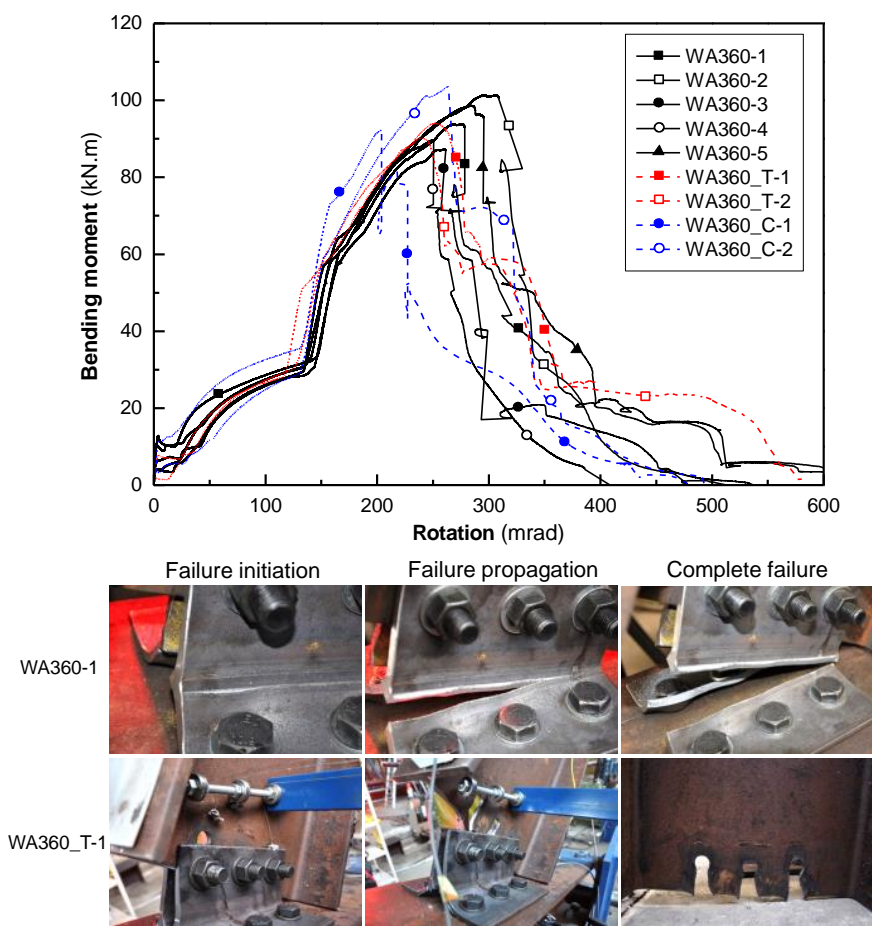

Fig. 9 Test results for WA360 series connections.

The combined bending and axial compression connections, i.e. WA360_C1 and WA360_C-2, had full-range behaviour similar to that of the bending connections, and failed in the same WAF mode. The additional compressive force delayed the failure of connection on the tensile side, thereby increasing the ultimate bending resistance, as shown in Fig. 9.

The combined bending and axial tension connections, i.e. WA360_T-1 and WA360_T-2, also behaved similarly to the bending connections except for the failure mode. Instead of having fracture initiation and propagation in the web angle cleats, the connections failed as a result of the significant plastic bearing deformation of the beam web at the bolt rows, and the subsequent shear-out of the bolts. The bolt at the top bolt row sheared-out first, marking the ultimate resistance of the joint. This was followed by the consecutive shear-out of the bolts at the remaining bolt rows, which generated a series of drops of bending resistance in the moment-rotation curve, as shown in Fig. 9. This failure mode is referred to as the bolt shear-out (BSO) mode. The additional tensile force reduced the ultimate bending resistance and the corresponding joint rotation.

Table 6

Summary of TSA530 series test results. [19]

\begin{tabular}{|c|c|c|c|c|c|c|}
\hline \multirow{2}{*}{ Designation } & \multirow{2}{*}{$\begin{array}{c}\text { Initial stiffness } \\
(\mathrm{kN} \cdot \mathrm{m} / \mathrm{rad})\end{array}$} & \multicolumn{2}{|c|}{ Ultimate resistance } & \multirow{2}{*}{$\begin{array}{c}\text { Joint rotation at ultimate } \\
\text { resistance } \\
(\mathrm{rad}) \\
\end{array}$} & \multirow{2}{*}{$\begin{array}{c}\text { Joint ductility } \\
\text { (rad) }\end{array}$} & \multirow{2}{*}{ Failure mode } \\
\hline & & Bending moment $(\mathrm{kN} \cdot \mathrm{m})$ & Axial force ${ }^{\#}(\mathrm{kN})$ & & & \\
\hline TSA530-1 & 13300 & 185 & 20.9 & 0.0969 & 0.0987 & TAF \\
\hline TSA530-2 & 14900 & 187 & 21.5 & 0.0981 & 0.103 & TAF \\
\hline TSA530-3 & 15100 & 157 & 15.2 & 0.0822 & 0.0869 & TAF \\
\hline TSA530-4 & 37100 & 170 & 16.0 & 0.0828 & 0.0857 & TAF \\
\hline TSA530-5 & 38100 & 157 & 12.6 & 0.0768 & 0.0795 & TAF \\
\hline TSA530_T-1 & 13200 & 165 & 55.6 & 0.0754 & 0.0819 & TAF \\
\hline TSA530_T-2 & 13200 & 156 & 53.8 & 0.0820 & 0.0856 & TAF \\
\hline TSA530_C-1 & 66700 & 215 & -61.1 & 0.0932 & 0.0968 & TAF \\
\hline TSA530_C-2 & 70200 & 223 & -59.9 & 0.0867 & 0.0915 & TAF \\
\hline
\end{tabular}

* TAF $=$ Top angle fracture

\# Positive values indicate tension; negative values indicate compression 


\subsection{WA460 series tests}

Figure 10 presents the bending moment versus joint rotation curves of all WA460 series connections and pictures showing the connection failure process. There was only one failure mode for the WA460 series connections, i.e. the WAF mode. Table 8 summarises the experimental results.

In general, the bending connections WA460-1 to WA460-5 behaved similarly to the WA360 bending connections over the full loading range. The moment-rotation curves had an initial linear range, a near-plateau caused by the slip of bolts, a nonlinear range primarily associated with the gradual yielding of the web angle cleats, a hardening range after the beam bottom flange came into contact with the column flange, and a resistance reduction range due to the initiation and propagation of cracks in the angle cleats, as shown in Fig. 10. As a result of the greater number of bolt rows and the longer web angle cleats, the WA460 connections had significantly larger resistances than the WA360 connections. Variabilities in connection behaviour were observed in the nominally identical connections. The CoVs of the initial stiffness, ultimate bending resistance, joint rotation corresponding to the ultimate resistance, and joint ductility were $0.081,0.033,0.070$ and 0.082 , respectively. It is noted that the above CoVs were consistently smaller than those for the WA360 bending connections, implying comparatively smaller variation in the moment-rotation behaviour of the WA460 connections.

The combined bending and axial force connections, i.e., WA460_T-1 and WA460_T-2 subjected to combined bending and tension, and, WA460_C-1 and WA460_C-2 subjected to combined bending and compression, all behaved similarly to the bending connections, having moment-rotation curves with similar shapes as shown in Figs. 10, and sharing the same WAF failure mode. The additional compressive force in the WA460_C-1 and WA460_C-2 connections delayed the failure of the connection on the tensile side, thereby increasing the ultimate bending resistance in comparison with the bending connections, as shown in Fig. 10. In the tests of the WA460_T-1 and WA460_T-

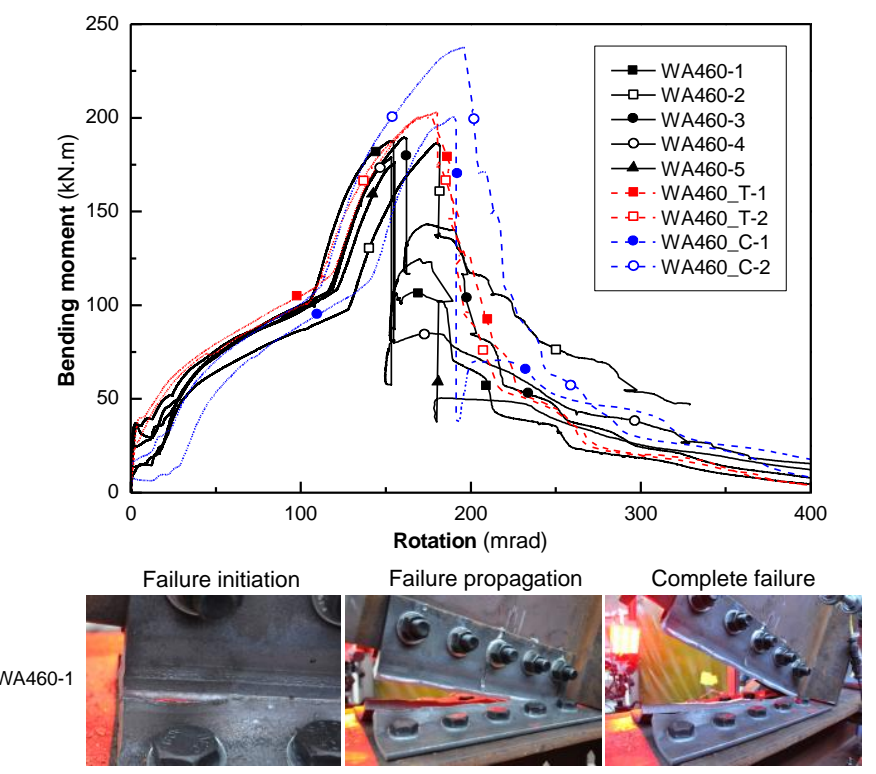

Fig. 10 Test results for WA460 series connections.

Table 7

Summary of WA360 series test results. [20]

\begin{tabular}{|c|c|c|c|c|c|c|}
\hline \multirow{2}{*}{ Designation } & \multirow{2}{*}{$\begin{array}{l}\text { Initial stiffness } \\
\qquad(\mathrm{kN} \cdot \mathrm{m} / \mathrm{rad})\end{array}$} & \multicolumn{2}{|c|}{ Ultimate resistance } & \multirow{2}{*}{$\begin{array}{c}\text { Joint rotation at ultimate } \\
\text { resistance } \\
(\mathrm{rad})\end{array}$} & \multirow{2}{*}{$\begin{array}{c}\text { Joint ductility } \\
\text { (rad) }\end{array}$} & \multirow{2}{*}{ Failure mode } \\
\hline & & Bending moment $(\mathrm{kN} \cdot \mathrm{m})$ & Axial force ${ }^{\#}(\mathrm{kN})$ & & & \\
\hline WA360-1 & 4550 & 93.7 & 20.6 & 0.277 & 0.500 & WAF \\
\hline WA360-2 & 2830 & 101 & 23.2 & 0.308 & 0.405 & WAF \\
\hline WA360-3 & 2970 & 87.3 & 18.6 & 0.261 & 0.438 & WAF \\
\hline WA360-4 & 3510 & 89.6 & 19.1 & 0.250 & 0.350 & WAF \\
\hline WA360-5 & 3630 & 98.6 & 22.9 & 0.287 & 0.511 & WAF \\
\hline WA360_T-1 & 3045 & 94.0 & 31.7 & 0.252 & $0.397^{\# \#}$ & BSO \\
\hline WA360_T-2 & 3211 & 90.3 & 30.6 & 0.239 & 0.551 & BSO \\
\hline WA360_C-1 & 4293 & 92.3 & -18.8 & 0.215 & 0.377 & WAF \\
\hline WA360_C-2 & 4704 & 104 & -19.9 & 0.275 & 0.408 & WAF \\
\hline
\end{tabular}

$* \mathrm{WAF}=\mathrm{Web}$ angle fracture $; \mathrm{BSO}=$ Bolt shear-out

\# Positive values indicate tension; negative values indicate compression

\#\# Loading was terminated when fracture in web angle propagated to the bottom bolt row; this rotation was the last recorded rotation

Table 8

Summary of WA460 series test results. [20]

\begin{tabular}{|c|c|c|c|c|c|c|}
\hline \multirow{2}{*}{ Designation } & \multirow{2}{*}{$\begin{array}{l}\text { Initial stiffness } \\
\quad(\mathrm{kN} \cdot \mathrm{m} / \mathrm{rad})\end{array}$} & \multicolumn{2}{|c|}{ Ultimate resistance } & \multirow{2}{*}{$\begin{array}{l}\text { Joint rotation at ultimate } \\
\text { resistance } \\
(\mathrm{rad})\end{array}$} & \multirow{2}{*}{$\begin{array}{c}\text { Joint ductility } \\
\text { (rad) }\end{array}$} & \multirow{2}{*}{ Failure mode } \\
\hline & & Bending moment $(\mathrm{kN} \cdot \mathrm{m})$ & Axial force ${ }^{\#}(\mathrm{kN})$ & & & \\
\hline WA460-1 & 12000 & 188 & 26.7 & 0.154 & 0.288 & WAF \\
\hline WA460-2 & 9990 & 186 & 29.0 & 0.180 & $0.329^{\# \#}$ & WAF \\
\hline WA460-3 & 11900 & 190 & 27.0 & 0.161 & 0.326 & WAF \\
\hline WA460-4 & 11500 & 179 & 25.7 & 0.153 & 0.362 & WAF \\
\hline WA460-5 & 10400 & 176 & 23.6 & 0.155 & 0.343 & WAF \\
\hline WA460_T-1 & 10445 & 202 & 60.6 & 0.176 & 0.312 & WAF \\
\hline WA460_T-2 & 9047 & 203 & 62.7 & 0.180 & 0.296 & WAF \\
\hline WA460_C-1 & 10772 & 201 & -45.3 & 0.203 & 0.390 & WAF \\
\hline WA460_C-2 & 12285 & 238 & -50.6 & 0.216 & 0.361 & WAF \\
\hline
\end{tabular}

$* \mathrm{WAF}=\mathrm{Web}$ angle fracture

\# Positive values indicate tension; negative values indicate compression

\#\# Loading was terminated when fracture in web angle propagated to the bottom bolt row; this rotation was the last recorded rotation 
2 connections, the additional tensile force also increased the ultimate bending resistance by about $10 \%$. This was surprising as the additional tensile force was expected to accelerate the failure of the tensile part of the connection, leading to a lower ultimate strength. Further investigations involving finite element fracture simulations are needed in order to explain this result.

\subsection{Failure mechanism}

The tested double web angle connections showed two failure modes, i.e. the web angle fracture (WAF) mode as shown in Fig. 11 and the bolt shear-out (BSO) mode as shown in Fig. 12. Both failure modes were induced by the tensile load transferred through the tensile (top) part of the angles. The connection would fail in the mode associated with the lowest ultimate resistance.



Fig. 11 Web angle fracture failure mode.

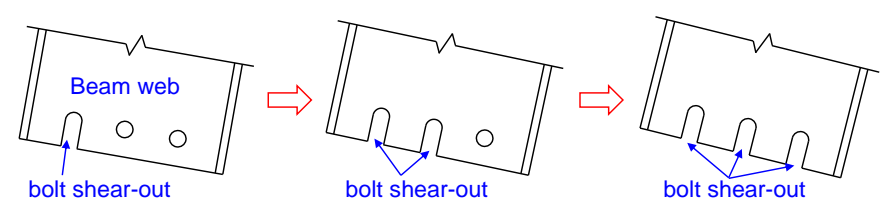

Fig. 12 Bolt shear-out failure mode.

The WAF failure mode dominated in the connections in which the web angle had a comparatively smaller resistance. In this failure mode, the crack occurred near the root of the angle cleat where the cleat thickness changed, which was similar to the TAF failure mode observed in the TSA series connections. But unlike in the TSA connections in which the crack could form either in the column leg or in the beam leg of the angle cleat, the crack in the

\section{References}

[1] de Lima L.R.O., Simões da Silva L., da S. Vellasco P.C.G. and de Andrade S.A.L., "Experimental evaluation of extended endplate beam-to-column joints subjected to bending and axial force", Engineering Structures, 26 (10), 1333-1347, 2004

[2] Girão Coelho A.M., Bijlaard F.S.K. and Simões Da Silva L., "Experimental assessment of the ductility of extended end plate connections", Engineering Structures, 26, 1185-1206, 2004

[3] Cabrero J.M. and Bayo E., "The semi-rigid behaviour of three-dimensional steel beam-tocolumn joints subjected to proportional loading. Part I. Experimental evaluation", Journal of Constructional Steel Research, 63 (9), 1241-1253, 2007.

[4] Stelmack T.W., Marley M.J. and Gerstle K.H., "Analysis and tests of flexibly connected steel frames", Journal of Structural Engineering, 112 (7), 1573-1588, 1986.

[5] Pirmoz A., Khoei A.S., Mohammadrezapour E. and Daryan A.S., "Moment-rotation behavior of bolted top-seat angle connections", Journal of Constructional Steel Research, 65(4), 973984, 2009

[6] Pirmoz A., Danesh F. and Farajkhah V., "The effect of axial beam force on moment-rotation curve of top and seat angels connections", Structural Design of Tall and Special Buildings, 20(7), 767-783, 2011.

[7] Hong K., Yang J.G. and Lee S.K., "Moment-rotation behavior of double angle connections subjected to shear load", Engineering Structures, 24(1), 125-132, 2002.

[8] Abolmaali A., Kukreti A.R. and Razavi, H., "Hysteresis behavior of semi-rigid double web angle steel connections", Journal of Constructional Steel Research, 59(8), 1057-1082, 2003.

[9] Gong Y.L., "Single-angle all-bolted shear connection", Journal of Constructional Steel Research, 65(6), 1337-1345, 2009.

[10] Asawasongkram N., Chomchuen P. and Premthamkorn P., "Development and application of a mechanical model of beam-to-column connections of steel storage racks", Advanced Steel Construction, 15(3), 297-305, 2019.
WA connections consistently formed in the beam leg, as shown in Fig. 11.

For the connections in which the bolts in bearing had smaller resistance than the web angle in bending, the BSO failure mode occurred, as shown in Fig. 12. Prior to the bolt shear-out, significant plastic bearing deformations developed at the edges of the bolt holes in the beam web.

\section{Conclusions}

This paper summarises recent experimental studies undertaken at the University of Sydney aiming at determining the full-range behaviour of three types of steel beam-to-column connections.

The experimental program comprised tests of 13 bolted extended end-plate (EP) connections, 18 top-and-seat angle (TSA) connections and 18 web angle (WA) connections. The connections were subjected to a variety of load combinations, including major-axis bending, combined bending and axial force, and bi-axial bending. Each connection was tested well into the post-ultimate range until complete failure, and thus the full-range behaviour of the connection was obtained, including the initial linear response, the non-linear behaviour resulting from the gradual yielding of the connection components, and the ultimate state and post-ultimate softening and fracture behaviour. Moreover, for the TSA and WA connections, multiple tests were conducted on nominally identical connections, so as to investigate the uncertainties in the full-range joint behaviour due to random variations in geometric and material properties.

The observed failure modes of the connections and experimental data defining the full-range moment-rotation curves are summarised. The tested EP10 connections showed the end-plate fracture failure mode featuring propagation of fracture along welds, while the tested EP20 connections failed in the column web buckling failure mode associated with a gradual resistance reduction in the post-ultimate range. The tested TSA connections failed in a top angle fracture failure mode, in which the fracture initiated and propagated quickly along the root of the cleat, leading to an instant drop of the bending resistance for the connections. The tested WA360 connections showed two failure modes, including the web angle fracture failure mode and the bolt shearout failure mode. Both failure modes resulted from the tensile load transmitted through the top part of the angles. Similar ultimate bending resistances and postultimate responses were observed for the two failure modes. The WA460 connections all failed in the web angle fracture failure mode.

\section{Acknowledgement}

The work presented in this paper was funded by the Australian Research Council, Discovery Project DP150104873.

[11] Zhang Y., Li Q., Huang W., Jiang K. and Sun Y., "Behavior of prefabricated beam-column connection with short strands in self-centering steel frame", Advanced Steel Construction, 15(2), 203-214, 2019.

[12] Torbaghan M., Sohrabi M. and Kazemi H., "Investigating the behavior of specially prefabricated steel moment connection under cyclic loading", Advanced Steel Construction, 14(3), 412-423, 2018.

[13] Simões da Silva L., Coelho A.G. and Lucena Neto E., "Equivalent post-buckling models for the flexural behaviour of steel connections", Computers \& Structures, 77(6), 615-624, 2000

[14] Lee S.S. and Moon T.S., "Moment-rotation model of semi-rigid connections with angles", Engineering Structures, 24(2), 227-237, 2002.

[15] Yang J.G. and Lee G.Y., "Analytical models for initial stiffness and ultimate moment of a double angle connection", Engineering Structures, 29(4), 542-551, 2007.

[16] CEN (European Committee for Standardization), EN 1993-1-8, Eurocode 3: design of steel structures, Part 1-8: design of joints, European Committee for Standardization, Brussels, 2010.

[17] Zhu C., Rasmussen K.J.R. and Yan S., "Generalised component model for structural steel joints", Journal of Constructional Steel Research, 153, 330-342, 2019.

[18] Zhu C., Rasmussen K.J.R., Yan S. and Zhang H., "Experimental full-range behavior assessment of bolted moment end-plate connections", Journal of Structural Engineering, 145(8), 04019079, 2019.

[19] Yan S., Jiang L., Rasmussen K.J.R. and Zhang H., "Full-range behaviour of top-and-seat angle connections", submitted to Journal of Structural Engineering.

[20] Yan S., Jiang L., Rasmussen K.J.R., "Full-range behaviour of double web angle connections", Journal of Constructional Steel Research, 166, 105907, 2020.

[21] Standards Australia, AS/NZS 3679.1, Structural steel Part 1: Hot-rolled bars and sections, Standards Australia, Sydney, Australia, 2010 